
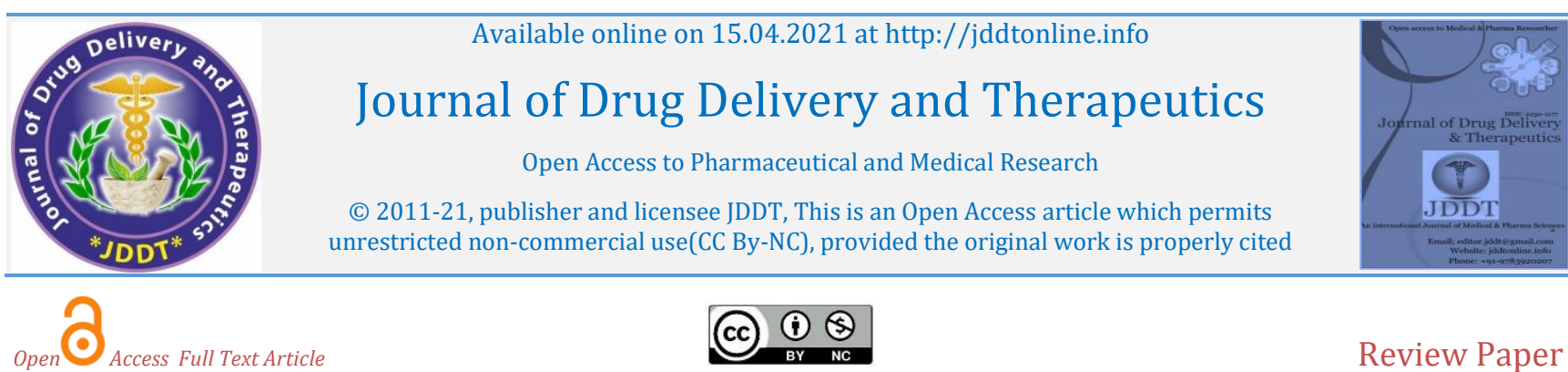

Review Paper

\title{
New Era of Formulation as Silver Nanoparticles in Pharma
}

\author{
Abhishek Soni, Ajay Kumar*, Ashish Kumar, Amit Choudhary, Happy \\ Department of Pharmaceutics, School of Pharmacy, Abhilashi University, Chail Chowk Distt. Mandi (H.P.), India
}

\section{Article Info:

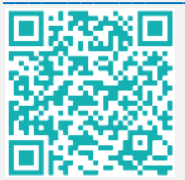 \\ Article History: \\ Received 07 Feb 2021 \\ Review Completed 22 March 2021 \\ Accepted 27 March 2021 \\ Available online 15 April 2021 \\ Cite this article as: \\ Soni A, Kumar A, Kumar A, Choudhary A, Happy, New Era of Formulation as Silver Nanoparticles in Pharma, Journal of Drug Delivery and Therapeutics. 2021; 11(2-s):126-131 \\ DOI: http://dx.doi.org/10.22270/jddt.v11i2-s.4643}

\section{Abstract}

In various fields of science, nanoparticles of noble metals, particularly silver nanoparticles, have been widely used. Its specific properties, which can be integrated into the materials of biosensors, composite fabrics, cosmetics, antimicrobial applications, conducting materials, and electronic components, make it a very interesting topic to be studied in the fields of chemistry, biology, healthcare, electronics, and other related fields. Such unique features depending on the size, and shape of the silver nanoparticles. Various methods of preparation for the synthesis of silver nanoparticles have been reported, such as electron irradiation, laser ablation, chemical reduction and biological methods.

Keywords: silver nanoparticles (AgNPs), particle size, localized surface plasmonic resonance (LSPR), characterization, application

*Address for Correspondence:

Ajay Kumar, Scholar of Pharmaceutics, Department of Pharmaceutics, School of Pharmacy, Abhilashi University, Chail Chowk Distt. Mandi (H.P.) 175028

\section{INTRODUCTION}

A particle with a nanometre range of 1-100 nm represents nanoparticles. Compared to its bulk structure, the nanoscale material has fresh, special, and superior physical and chemical properties due to an improvement in the surface area ratio per material/particle volume. ${ }^{1}$ Metal nanoparticles are the most widely studied nanoparticle materials because they are easier to synthesize. Also, there is a wide range of applications for these materials: detectors, catalysts, surface coating agents, antibacterial/antimicrobials, among many others. Silver $(\mathrm{Ag})^{2}$, gold $(\mathrm{Au})^{3}$, platinum $(\mathrm{Pt})^{4}$, and palladium $^{5}$ are some of the most studied metallic nanoparticles. Nanoparticles produced and characterized due to their inherent characteristic of acting as an antimicrobial agent even in a solid-state, Ag NPs assume an important role. While its value was recognized much earlier, except its use in oriental medicine and coins, it was not well utilized. Almost 320 tons of Ag NPs are expected to be produced per year and used in nanomedical imaging, biosensing, and food products. ${ }^{6}$

\section{SILVER NANOPARTICLES}

Due to their chemical stability, catalytic activity, localized surface plasma resonance, and high conductivity, silver nanoparticles have attracted growing interest. ${ }^{7}$ Besides, previous reports showed that the reactive oxygen species (ROS) produced under certain conditions at the surface of the silver nanoparticles or by the released free silver ions may cause cell death of either mammalian or microbial cells, giving specific antibacterial and antifungal effects to the silver nanoparticles. ${ }^{8}$ Silver nanoparticles have great potential to prevent wound inflammation and thus facilitate wound healing in the form of topical administration based on these effects. The skin penetration ability and protection of silver nanoparticles should be tested for topical use. Compared to other inorganic metal nanoparticles such as gold, the skin penetration potential of silver nanoparticles is much smaller, as a higher percentage of free ions in the outermost layers of the stratum corneum are precipitated as Ag-S. TEM micrographs showed that the deepest layers of the stratum corneum could be passively penetrated by silver nanoparticles. ${ }^{9}$

Researchers have recently conducted an in-depth study on the excellent function of silver nanoparticles such as photoelectricity ${ }^{10}$, catalysis ${ }^{11}$ antibacterial agents ${ }^{12}$, biosensors ${ }^{13}$, and surface-enhanced Raman dispersion (SERS). ${ }^{14}$ Through chemical reduction ${ }^{15}$, photo reduction ${ }^{16}$, and laser synthesis ${ }^{17}$, etc. Therefore, it is increasingly necessary to develop simple and economical methods by which the scale, shape, and size distribution of AgNPs can be finely controlled. An efficient way to make AgNPs with good stability and dispersibility is to use protective agents. Until then, protective agents can prevent agglomeration between particles. So, it is important to use protective agents for the synthesis of AgNPs. ${ }^{18}$

\section{SYNTHESIS OF SILVER NANOPARTICLE}

Silver nanoparticles are generally synthesized by two approaches,
(a) Top to bottom approach
(b) Bottom to top approach 


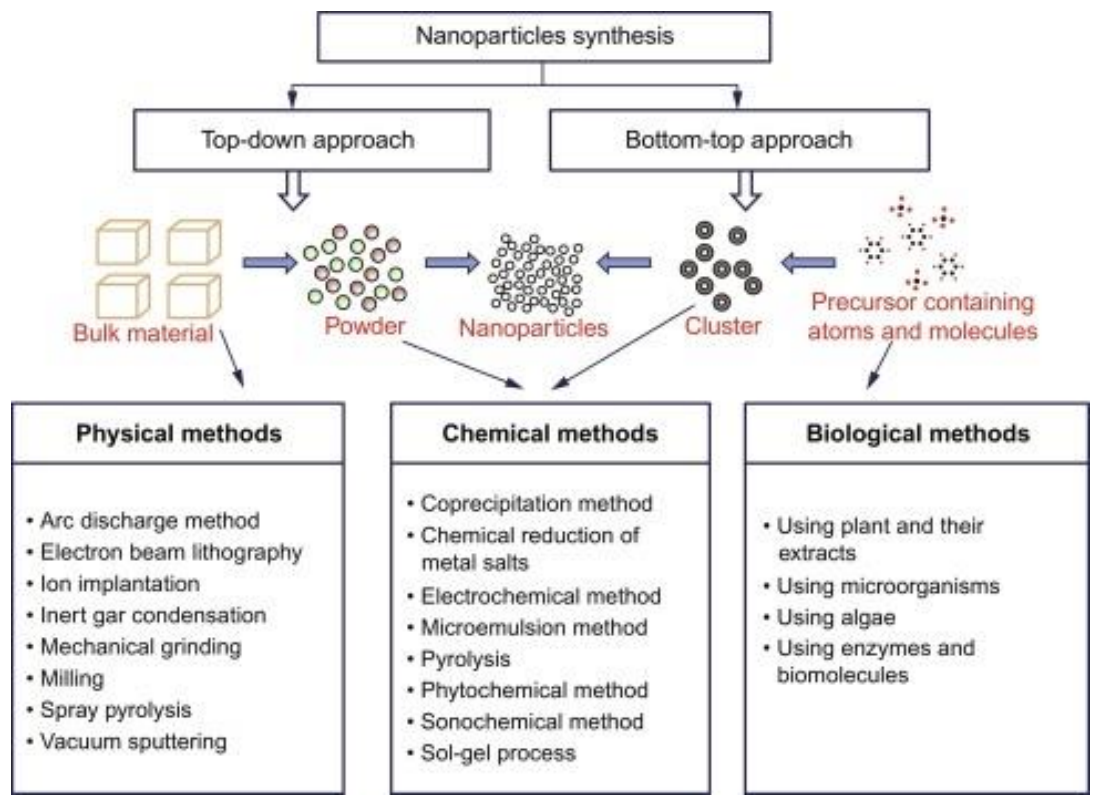

Figure 1: Synthesis of Nanoparticles

In top to bottom approach, the suitable bulk material is broken down into smaller fine particles by size reduction using various techniques like grinding, milling, sputtering, thermal/laser ablation, etc., thus the "top-down" method comprises of mechanical grinding of bulk metals with subsequent stabilization using colloidal protecting agents while in the bottom to top approach, nanoparticles are synthesized using chemical and biological methods by self-assembly of atoms to new nuclei, which grow into nanosize particles while the "bottom-up" methods include chemical reduction, electrochemical methods and sonodecomposition. ${ }^{19}$ The biggest advantage of the "bottom to top" approach method is the production of a large number of nanoparticles within a short period. The major advantage of chemical methods is a high yield, contrary to physical methods, which have a low yield. In the case of the "top to bottom," approach nanoparticles are generally synthesized by evaporation condensation technique with the help of a tube furnace at atmospheric pressure. In this method, the primary material placed centered at the furnace is vaporized into a carrier gas, within a boat. One of the biggest limitations of this method is the imperfections in the surface structure of the product and the other physical properties of nanoparticles are highly dependent on the surface structure of surface chemistry. Hence, a cost-effective and environment-friendly alternate synthetic route was inevitable that culminated into the green syntheses. ${ }^{20}$

\section{Green synthesis}

Green nanoparticle synthesis is progressively identified as a significant nanotechnology field in which nanoparticles are produced with the help of biological organisms such as microorganisms, plant extracts, or plant biomass and could be an environmentally friendly substitute for chemical and physical methods. Green synthesis is chosen over physical and chemical approaches as the former is environmentally sustainable, cost-effective, large-scale syntheses can be easily scaled, no high temperature, energy, and toxic chemicals need to be used. Due to the ease of improvement, the less biohazard, and the strenuous method of maintaining cell cultures as needed in the microorganism process, the use of plant extracts is potentially advantageous over microorganisms. ${ }^{19}$

\section{MECHANISM OF ACTION OF SILVER NANOPARTICLES}

The exact mechanism of the antimicrobial properties of silver nanoparticles is not yet known. Silver nanoparticles bind and penetrate the bacterial cell wall, causing structural changes in the cell membrane, such as cell membrane permeability and cell death. Another mechanism of action of silver nanoparticles is the formation of free radicals by AgNPs causing the cell's death. The formation of free radicals is indicated by resonance studies of electron spin. Free radicals can damage the cell membrane when in contact with bacteria, rendering it porous, which finally leads to cell death. ${ }^{21}$ Due to their large surface area that provides better contact with microorganisms, silver nanoparticles show effective antimicrobial properties compared to other salts. The release of silver ions by nanoparticles in the bacterial cells improves their bactericidal activity. ${ }^{22}$
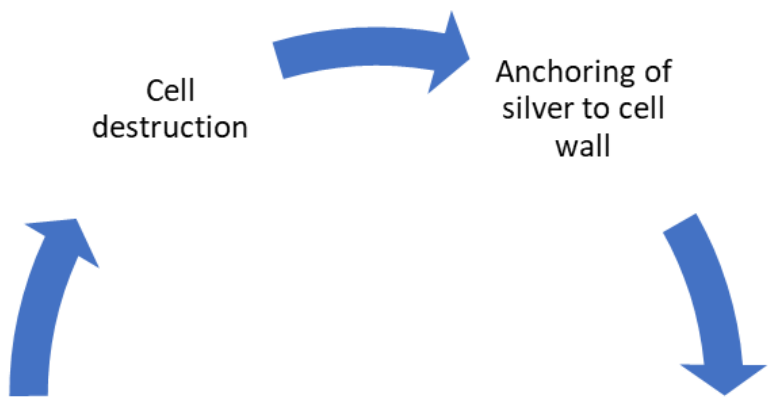

Relese of reactive Free radicle oxygen causesmembr ane disruptoin 


\section{Pharmacokinetics of silver nanoparticles}

For enhanced therapeutic effects, primary absorption of drugs or nanoparticles in the target tissue is always beneficial and, conversely, a high degree of distribution to non-target tissues may cause unwanted toxic effects and should be avoided. Therefore, for the safe and effective biomedical applications of nanoparticles, pharmacokinetic and tissue bio-distribution data are crucial. ${ }^{23}$

\section{Absorption}

The nanoparticle absorption process is more complex than that of small molecules. Paracellular transport, transcytosis, and $\mathrm{M}$ cell uptake in the GI tract will absorb nanoparticles that are administered orally, whereas macrophages and lymphatic uptake absorb mainly subcutaneous, intramuscular, or inhaled nanoparticles. ${ }^{24}$

\section{Distribution}

The in vivo distribution of nanoparticles depends on various transport mechanisms, such as opsonization, the formation of the protein corona, the absorption of mononuclear phagocytes (MPS), the enhanced permeability and retention (EPR) effect, target-mediated disposal, and the transport of lymph. ${ }^{24}$ The liver was identified as the primary organ of the delivery of Ag followed by the spleen and kidneys, whether oral, intravenous, subcutaneous, or inhaled exposure. Silver accumulation in the liver, including Kupffer cells, hepatocytes, and sinusoidal endothelium cells, has been detected in several cell types. The silver deposition has been observed in all regions of the kidney, including the cortex, medulla, inner medulla, and cortical glomeruli, and genderrelated differences in silver accumulation have been documented in rat kidneys after repeated oral exposure, with double inflation in females compared with males. ${ }^{23}$

\section{Metabolism}

After oral exposure to both ionic and nanoparticulate silver suspensions, silver has been reported to be deposited as particles in tissue, such as the skin epidermis, the glomeruli, and the intestines. The particle size of these nanoparticles in the rat intestine has been reported to be $12 \mathrm{~nm}$ in diameter and to contain sulfur and selenium in addition to silver. Ag+ can react with GSH, creating $\mathrm{H}+$ and GS-Ag, which eventually form polymer complexes of Ag-GSH, followed by division into different tissues.

Ag-thiol complexes can also be reduced to zero-valent AgNPs in visible light at slower rates when UV-photodecomposition takes place. In the production of Ag2S NPs, in addition to thiols, AgNPs can be sulphidized. Ag2S NPs are also capable of interacting with selenium for the production of Ag2Se NPs and $\mathrm{Ag} / \mathrm{S} / \mathrm{Se}$ argyrial particles. ${ }^{23}$

\section{Elimination}

Researchers found low silver excretion in urine 0.1 percent of $24 \mathrm{~h}$ intake for both groups) but high excretion of silver in faeces (63 and 49 percent of the daily dose for AgNPs and silver acetate groups, respectively) after a 28-days ${ }^{23}$ repeated oral exposure to $14 \mathrm{~nm}$ PVP-coated AgNPs or silver acetate in rats. Excretion of faeces: $14 \mathrm{~nm}$ AgNP has a higher faecal excretion rate than ionic silver after oral administration, with 63 and 49 percent for nanoparticles and ionic silver, respectively. This was due to the lower bioavailability of silver nanoparticles. ${ }^{26}$

Urinary excretion: East et al. found that a woman's urinary excretion of an orally administered dose of radioactive silver tracer was between 2 and $41 \%$ after 12 hours. ${ }^{25}$
Following orally administered 110 radionuclide of silver, Furchner et al. registered silver excretion in the urine. ${ }^{27}$ After 8 weeks with post-oral dosing of silver or silver nanoparticles (15 and $20 \mathrm{~nm}$ ), Van der Zande et al. discovered that silver was still present in the rat brain and testes. ${ }^{28}$

\section{CHARACTERIZATION TOOLS FOR ANALYSIS OF SILVER NANOPARTICLES}

\section{X-ray diffraction spectroscopy (XRD)}

With X-ray diffraction spectroscopy you can determine the crystalline construction, size, and shape of the unit cell and material crystallite sized (XRD). The peaks of x-ray diffraction in the face-centered metal-faced cubes of silver (fcc) respectively at $2 \theta=38.00,44.16,64.40$, and 77.33 were generally observed, which corresponded to (111), (200), (220), and (311). The crystalline size of the particulate can be estimated by using the Debye-Scherrer formula $d=0.89$ $\cos \theta$, where $d$ is the particle size, is the wavelength of X-ray radiation $(1.5406 \AA)$, is the full-width at half maxima (FWHM) of the strongest peak (in radians) of the diffraction pattern and 2 is the Bragg angle. ${ }^{29}$

\section{Scanning electron microscopy (SEM)}

In the process, a scan with a fine, concentrated beam of electrons and electrostatic or electromagnetic lenses analyzes the entire sample to create much higher resolution images. The sample surface morphology is determined using secondary electrons generated from the surface of the sample.

\section{Transmission electron microscope (TEM)}

In TEM, an incident electron beam is transmitted through an ultra-thin sample which interacts with the sample and transforms into undisputed electrons or elastically dispersed electrons. The dispersed and dispersed electrons are centered by a series of electromagnetic lenses and then projected onto a screen to generate electrons diffraction, amplitude contrast, a phase-contrast picture, or a shadow image with different darkness depending on the density of dispersed electrons. Techniques of transmission electron microscopy can provide the atomical or sub-nanometer spatial-resolution, either simultaneously or based on a serial method, direct imaging, diffraction, and spectroscopic information, and chemical composition. In combination with nano diffraction, scanning tunneling microscopy (STM), atomic resolution electron energy loss spectroscopy, and nanometer resolution X-ray energy dispersive spectroscopy techniques, high-resolution TEM imaging is crucial to fundamental nanoscience and nanotechnology studies.

Different surface structures can be obtained from various synthesis routes. The surface morphology of the nanostructural features of silver is examined using the above electron microscopic techniques. ${ }^{30}$

\section{Atomic force microscopy (AFM)}

The AFM can analyze nanomaterials' size, shape, structure, sorption, and dispersion. It is based on the physical scan of submicron-level samples (contact- or non-contact mode) using a probe tip of the atomic dimension and provides ultrahigh-resolution measuring ( $>100$ times higher than visual diffraction). One of the main advantages of this nondestructive technology is that it commends the imaging of non-dirigent specimens without pre-treatment or significant damage to the surface. ${ }^{31}$

The major drawbacks of this technique are 
The curved tip generally exceeds the nanomaterial dimensions to be examined and the lateral dimensions of the samples are overestimated. ${ }^{32}$

The capacity of AFM is also insufficient to detect or locate particular molecules; however, recent advances in single molecular force spectroscopy with AFM cantilever tips containing a ligand have eliminated this disadvantage. ${ }^{32}$

\section{UV-Visible spectroscopy analysis}

Due to their excellent optical properties, such as surfaceenhanced scattering of Raman (SERS) and the surface plasmonic resonance that strongly depend on their size, form, and composition, the synthesis of silver nanostructures has become an active research field for decades. They can be checked using optical analyses such as XPS and UV-visible spectroscopy. While the color change from silver to silver nanoparticles was visually observed, the UV visible spectrophotometer was used to monitor the silver nanoparticle's stability. Standard feature Due to the interband $4 \mathrm{~d}-5 \mathrm{sp}$ transitions, the UV-Vis spectrum peak of bulk Ag occurs at $320 \mathrm{~nm}^{33}$ and the red change in this peak to about $420 \mathrm{~nm}$ was observed due to the occurrence of the plasmonic resonance phenomenon in the silver metal nanodispersion.

UV-Vis spectroscopy is also used for determining the particle size of silver nanoparticles, using the principle of Mie scattering. Using the following equation, the full width at the half limit of the optical spectra (Lorentz-shaped peak $\Omega$ ) can be used to measure the particle size of the stable suspension. ${ }^{34}$

$$
D=\frac{\left(\epsilon_{0}+2 n^{2}\right) c m U_{F}}{2 N_{c} e^{2} \omega}
$$

where, $\mathrm{w}$ is full width at half maxima of the Lorentz shaped peak, and E0, n, c, m, UF, Nc, e, and D, are the frequencyindependent dielectric constant, refractive index of water, velocity of light, the mass of an electron, electron velocity at the Fermi energy, number of electrons per unit volume, the electron charge and diameter of the particle, respectively.

\section{Surface-enhanced Raman scattering spectroscopy (SERS)}

As a sensitive and selective tool for the identification of molecules, SERS can be used. Strong electromagnetic fields are produced when they are exposed to visible light due to the localized surface plasmon resonance (LSPR) of nanonoble metals. The induced dipole increases if the Raman scatterer is placed near these amplified nano-noble metal electromagnetic fields, increasing the intensity of the inelastic scattering. Similar links can be useful for the nanoparticle's extinction and dispersion cross-sections. If the nanoparticle's disappearance and dispersion cross-sections at resonant wavelengths are maximized, this reflects the spectroscopic signature of the excitation of the LSPR. In condensed phases, the SER spectrum also provides precise details on the molecular structure and local environment than any other electronic spectroscopy technique. ${ }^{35}$

\section{APPLICATIONS OF THE SILVER NANOPARTICLES}

Medical: diagnosis and treatment of aliment- The silver nanoparticles exhibit a broad spectrum of anti- bactericidal, antiviral, anti-inflammatory, antiangiogenic, anti-tumor, and anti-oxidative properties along with the biological and chemical sensing, imaging, drug carrier, and diagnosis of cancer/HIV/AIDS. ${ }^{36}$
Because of its antimicrobial properties, silver nanotechnology seems to have become a fast-growing technology in the field of orthopaedics. Therefore, silver nanoparticles can be used in orthopaedic applications such as trauma implants, tumor prostheses, bone cement, and hydroxyapatite coatings to prevent biofilm formation. Biofilm formation is a major source of morbidity in orthopaedic surgery. The promising results with in vitro and in vivo studies of the use of AgNPs in this field reduce the risk of infection in an effective and biocompatible manner. ${ }^{37}$

Food industry - Silver nanoparticles are now being used in dietary supplements, food packaging, and usable food products for a wide range of applications. Nanocomposite LDPE films containing Ag and $\mathrm{ZnO}$ nanoparticles packaging will be a safer, inert, cheaper to make, simple to dispose of, and reuse-way to protect food from dust, gases (02, C02), light, bacteria, and moisture. ${ }^{38}$

\section{Catalyst}

In recent years, one of the most important applications of silver nanoparticles has been observed in the catalysis of chemical reactions. Nanosilver catalysts have sparked interest in nano silver-mediated organic synthesis in recent years due to its interesting reactivity and selectivity, stability, and recyclability in catalytic reactions with atomeconomy and environmentally benign nature. Nanosilver of different shapes and sizes catalyzed many organic transformations such as cyclization, Michael addition, alkylation, alkynylation, oxidation, cross-coupling reaction, A3-coupling reaction, reduction, Friedel-crafts, Diel-Alder reaction, and many more. 39

\section{Air disinfection (bio-sols filter)}

Bioaerosols are biological source in the air, such as viruses, bacteria, and fungi that can cause bacterial, allergenic, or toxic diseases. The filters of heating, ventilating, and airconditioning (HVAC) systems accumulated large amounts of these bioaerosols. Bioaerosols were effectively removed using Ag-deposited-activated carbon filters (ACF) to minimise microbial growth in air filters. Bacillus subtilis and E. coli antibacterial activity of Ag-coated ACF filters were tested. 40

\section{Drinking water purification}

Studies supported that the silver nanoparticle can work as an excellent antiviral, antimicrobial, and disinfectant agent. Silver nanoparticles in surface water, groundwater, and brackish water were found to be stable, according to the findings. However, in seawater conditions, AgNP tends to aggregate. The comparison of silver nanoparticle-impregnated ceramic water filters and ceramic filters impregnated with silver nitrate was made. The results showed that silver nanoparticlesimpregnated ceramic water filters are more suitable for this application than silver nitrate-treated filters because the amount of silver desorbed is lower, without affecting the water chemistry conditions or filter efficiency. ${ }^{41}$

\section{General/health care}

Nano silver products such as beauty soap, hair shampoo and conditioner, body cleanser, toothbrush, sanitizer, facial mask sheets, a skincare line, makeup line, wet wipes, disinfectant spray, wash and laundry detergent, etc., have been influencing our daily life at great extent.42 Silver nanoparticles can also be incorporated in the manufacturing of toothpaste or oral care gels. Silver nanoparticles with particle size less than $15 \mathrm{~nm}$ and a concentration of $0.004 \%$ $\mathrm{w} / \mathrm{w}$ showed maximum efficiency to prevent the growth of 
bacteria that causes unpleasant oral smells and dental cavities. 43

The nanoproduct can also be used in the dyeing of cosmetic foundations, eye shadows, powders, lipsticks, inks, varnishes, or eyebrow pencils. According to Ha et al., the products with metal nanoparticles, unlike the conventionally used metallic pigments, are not harmful to human health, and may even have health benefits. ${ }^{44}$

\section{CONCLUSION}

Different approaches for planning AgNPs and their implementations are discussed in this study. Specifically, . Based on the importance of the silver NPs over other nanometals, their properties such as surface-enhanced plasmonic character, cost, stability, and so on were developed. In keeping AgNPs in mind, the methods of synthesis and advanced characterization techniques were also presented. This review article also explains the applications of these qualified nanoparticles along with their goodness and particular qualities. The challenges and potential prospects of this up-bringing region have eventually been discussed.

\section{REFERENCES}

1. Cushing BL, Kolesnichenko VL, O'connor CJ. Recent advances in the liquid-phase syntheses of inorganic nanoparticles. Chemical reviews. 2004 Sep 8; 104(9):3893-946.

2. Ajitha B, Reddy YA, Reddy PS. Green synthesis and characterization of silver nanoparticles using Lantana camara leaf extract. Materials science and engineering: C. 2015; 49:37381.

3. Dos Santos MM, Queiroz MJ, Baptista PV. Enhancement of antibiotic effect via gold: silver-alloy nanoparticles. Journal of Nanoparticle Research. 2012; 14(5):1-8.

4. Aritonang HF, Onggo D, Ciptati C, Radiman CL. Synthesis of platinum nanoparticles from $\mathrm{K} 2 \mathrm{PtCl} 4$ solution using bacterial cellulose matrix. Journal of Nanoparticles. 2014; 2014.

5. Raut RW, Haroon AS, Malghe YS, Nikam BT, Kashid SB. Rapid biosynthesis of platinum and palladium metal nanoparticles using root extract of Asparagus racemosus Linn. Adv Mater Lett. 2013; 4(8):650-4.

6. Chen X, Schluesener HJ. Nanosilver: a nanoproduct in medical application. Toxicology letters. 2008; 176(1):1-2.

7. Tran QH, Le AT. Silver nanoparticles: synthesis, properties, toxicology, applications and perspectives. Advances in Natural Sciences: Nanoscience and Nanotechnology. 2013; 4(3):033001.

8. Levard C, Hotze EM, Lowry GV, Brown Jr GE. Environmental transformations of silver nanoparticles: impact on stability and toxicity. Environmental science \& technology. 2012; 46(13):6900-14.

9. Larese FF, D’Agostin F, Crosera M, Adami G, Renzi N, Bovenzi M, Maina G. Human skin penetration of silver nanoparticles through intact and damaged skin. Toxicology. 2009; 255(12):33-7.

10. Evanoff DD, Chumanov G. Size-controlled synthesis of nanoparticles. 1. "Silver-only" aqueous suspensions via hydrogen reduction. The Journal of Physical Chemistry B. 2004; 108(37):13948-56.

11. Mallick K, Witcomb M, Scurrell M. Silver nanoparticle catalysed redox reaction: an electron relay effect. Materials chemistry and physics. 2006; 97(2-3):283-7.

12. Ahmed S, Ahmad M, Swami BL, Ikram S. A review on plants extract mediated synthesis of silver nanoparticles for antimicrobial applications: a green expertise. Journal of advanced research. 2016; 7(1):17-28.

13. Ren X, Meng X, Chen D, Tang F, Jiao J. Using silver nanoparticle to enhance current response of biosensor. Biosensors and Bioelectronics. 2005; 21(3):433-7.

14. Leopold N, Lendl B. A new method for fast preparation of highly surface-enhanced Raman scattering (SERS) active silver colloids at room temperature by reduction of silver nitrate with hydroxylamine hydrochloride. The Journal of Physical Chemistry B. $2003 ; 107(24): 5723-7$.
15. Zhang Z, Zhao B, Hu L. PVP protective mechanism of ultrafine silver powder synthesized by chemical reduction processes. Journal of Solid-State Chemistry. 1996; 121(1):105-10.

16. Jia H, Zeng J, Song W, An J, Zhao B. Preparation of silver nanoparticles by photo-reduction for surface-enhanced Raman scattering. Thin Solid Films. 2006; 496(2):281-7.

17. Mafune F, Kohno JY, Takeda Y, Kondow T, Sawabe H. Formation and size control of silver nanoparticles by laser ablation in aqueous solution. The Journal of Physical Chemistry B. 2000; 104(39):9111-7.

18. Wang H, Qiao X, Chen J, Wang X, Ding S. Mechanisms of PVP in the preparation of silver nanoparticles. Materials Chemistry and Physics. 2005; 94(2-3):449-53.

19. Ahmed S, Ahmad M, Swami BL, Ikram S. A review on plants extract mediated synthesis of silver nanoparticles for antimicrobial applications: a green expertise. Journal of advanced research. 2016; 7(1):17-28.

20. Zhang XF, Liu ZG, Shen W, Gurunathan S. Silver nanoparticles: synthesis, characterization, properties, applications, and therapeutic approaches. International journal of molecular sciences. 2016; 17(9):1534.

21. Prabhu S, Poulose EK. Silver nanoparticles: mechanism of antimicrobial action, synthesis, medical applications, and toxicity effects. International nano letters. 2012; 2(1):1-0.

22. Rai M, Yadav A, Gade A. Silver nanoparticles as a new generation of antimicrobials. Biotechnology advances. 2009; 27(1):76-83.

23. Lin Z, Monteiro-Riviere NA, Riviere JE. Pharmacokinetics of metallic nanoparticles. Wiley Interdisciplinary Reviews: Nanomedicine and Nanobiotechnology. 2015; 7(2):189-217.

24. Li M, Zou P, Tyner K, Lee S. Physiologically based pharmacokinetic (PBPK) modeling of pharmaceutical nanoparticles. The AAPS journal. 2017; 19(1):26-42.

25. East BW, Boddy K, Williams ED, Macintyre D, McLay AL. Silver retention, total body silver and tissue silver concentrations in argyria associated with exposure to an anti-smoking remedy containing silver acetate. Clinical and experimental dermatology. 1980; 5(3):305-11.

26. Hadrup N, Lam HR. Oral toxicity of silver ions, silver nanoparticles and colloidal silver-a review. Regulatory Toxicology and Pharmacology. 2014; 68(1):1-7.

27. Furchner JE, Richmond CR, Drake GA. Comparative metabolism of radionuclides in mammals-IV. Retention of silver-110m in the mouse, rat, monkey, and dog. Health Physics. 1968; 15(6):50514.

28. Van der Zande M, Vandebriel RJ, Van Doren E, Kramer E, Herrera Rivera Z, Serrano-Rojero CS, Gremmer ER, Mast J, Peters RJ, Hollman PC, Hendriksen PJ. Distribution, elimination, and toxicity of silver nanoparticles and silver ions in rats after 28day oral exposure. ACS nano. 2012; 6(8):7427-42.

29. Scherrer P. Nachrichten von der Gesellschaft der Wissenschaften zu Göttingen. Mathematisch-Physikalische Klasse. 1918; 2:98100.

30. Wiley B, Sun Y, Xia Y. Synthesis of silver nanostructures with controlled shapes and properties. Accounts of chemical research. 2007;40(10):1067-76.

31. Gmoshinski IV, Khotimchenko SA, Popov VO, Dzantiev BB, Zherdev AV, Demin VF, Buzulukov YP. Nanomaterials and nanotechnologies: methods of analysis and control. Russian Chemical Reviews. 2013; 82(1):48.

32. Tiede K, Boxall AB, Tear SP, Lewis J, David H, Hassellöv M. Detection and characterization of engineered nanoparticles in food and the environment. Food additives and contaminants. 2008; 25(7):795-821.

33. Henglein A. Physicochemical properties of small metal particles in solution:" microelectrode" reactions, chemisorption, composite metal particles, and the atom-to-metal transition. The Journal of Physical Chemistry. 1993; 97(21):5457-71.

34. Seney CS, Gutzman BM, Goddard RH. Correlation and characterization of three-dimensional morphologically dependent localized surface plasmon resonance spectra of single silver nanoparticles using dark-field optical microscopy and spectroscopy and atomic force microscopy. J. Phys. Chem. C. 2009; 113:74.

35. Liang H, Li Z, Wang Z, Wang W, Rosei F, Ma D, Xu H. Enormous Surface-Enhanced Raman Scattering from Dimers of Flower-Like Silver Mesoparticles. Small. 2012; 8(22):3400-5. 
36. Mirkin CA. Programming the assembly of two-and threedimensional architectures with DNA and nanoscale inorganic building blocks. Inorganic chemistry. 2000; 39(11):2258-72.

37. Brennan SA, Fhoghlú CN, Devitt BM. FJ O' mahony, D. Brabazon and A. Walsh. Bone Joint J. 2015; 97:582-9.

38. Jiang Z, Chen Y, Liang A, Tao H, Tang N, Zhong F. Silver nanoparticle labeled immunoresonance scattering spectral assay for trace fibrinogen. Science in China Series B: Chemistry. 2007; 50(3):345-50

39. Yan M. Nanoporous gold catalyst for highly selective semihydrogenation of alkynes: Remarkable effect of amine additives. InDevelopment of New Catalytic Performance of Nanoporous Metals for Organic Reactions 2014 (pp. 55-91). Springer, Tokyo.
40. Yoon KY, Byeon JH, Park CW, Hwang J. Antimicrobial effect of silver particles on bacterial contamination of activated carbon fibers. Environmental science \& technology. 2008; 42(4):1251-5.

41. Chouhan N. Silver nanoparticles: synthesis, characterization and applications.

42. Rai M, Birla S, Ingle AP, Gupta I, Gade A, Abd-Elsalam K, Marcato PD, Duran N. Nanosilver: an inorganic nanoparticle with myriad potential applications. Nanotechnology Reviews. 2014; 3(3):281-309.

43. Holladay RJ, inventor. Toothpaste or tooth gel containing silver nano particles coated with silver oxide. United States patent application US 2013; 13:135,575.

44. Chung BH, Lim YT, Kim JK, Jeong JY, Ha TH, inventors; Korea Research Institute of Bioscience, Biotechnology KRIBB, assignee. Cosmetic pigment composition containing gold or silver nanoparticles. United States patent application US 2009; 11:847,995. 